\title{
Editorial
}

\section{Una reflexión sobre la gripe de 1918-1919 en tiempos de la coviD-19}

Hace poco más de cien años se inició la gripe de 1918-1919, que ha sido calificada como "la madre de todas las pandemias" [1, p. 15], y cursó con tres brotes epidémicos: en la primavera y el otoño de 1918, y en la primavera de 1919. En la actualidad, se estima que esta grave crisis sanitaria fue responsable de entre 50 y 100 millones de personas fallecidas, con un predominio entre la población adulta joven (20-45 años), en vez de en mayores de 65 años y niños pequeños, como suele ser habitual [2].

Una de las primeras cuestiones que cabe preguntarse es por las razones que puedan explicar semejante mortalidad, cuando al inicio de la pandemia se le dio escasa importancia, por considerarla como algo banal, y unos años antes, la medicina hablaba de las enfermedades infecciosas como una patología evitable [3]. Este planteamiento derivaba de la aplicación de la doctrina bacteriológica, que admitía que, una vez aislado el germen responsable de la enfermedad, se podría preparar una vacuna específica como recurso profiláctico y un suero como tratamiento igualmente específico.

Además del papel que se pueda atribuir al virus causante de la pandemia de 1918, que parece provocó una importante reacción inflamatoria pulmonar en los casos graves, como ahora está ocurriendo con las neumonías por COVID-19, es preciso tener en cuenta el contexto histórico, político y socioeconómico en el que se desarrolló la pandemia. Recordemos que el primer brote y parte del segundo ocurrieron durante la Primera Guerra Mundial y estuvieron condicionados por ella. De hecho, la censura militar operante en los países que participaban en la contienda silenció la presencia de la gripe en ellos, y no admitieron su existencia hasta después de que España comunicara el inicio de la epidemia en el país a las autoridades sanitarias internacionales. Esto motivó que esta pandemia recibiera el nombre de "gripe española" y pasara así a la historia.

La Primera Guerra Mundial implicó un gran movimiento de población militar, en condiciones de hacinamiento en los transportes y en las trincheras, que soportó malas condiciones higiénico-sanitarias y alimentarias, o los gases de las armas químicas utilizadas por primera vez. Estos elementos facilitaron la difusión de la enfermedad y su mayor gravedad en la población adulta-joven. Además, hubo importantes movimientos de población civil por la contienda y su impacto en los sectores productivos. Se desplazaron trabajadores de países no participantes en la guerra, para trabajar en la agricultura y en otros entornos de los países contendientes. Dichos trabajadores, particularmente los temporeros, se expusieron a la gripe y sirvieron también de vehículos de la epidemia hacia sus lugares de origen, al retornar tras la conclusión de sus tareas.

Otro elemento concurrente fue la crisis social y económica, con un marcado impacto entre las clases populares de modo bastante global, alcanzando no solo a los países contendientes, sino también a los que mantuvieron una posición neutral, como España. La situación de bloqueo comercial durante el conflicto bélico se tradujo en escasez y encarecimiento de productos de primera necesidad, que empeoró con la pandemia, siendo particularmente grave el acceso a los alimentos y medicamentos.

En el contexto descrito, la respuesta médica distó de ser tan positiva como se esperaba. No fue solo la falta de profesionales sanitarios, agravada en los países beligerantes por el desplazamiento de parte de sus efectivos a los escenarios de guerra y, en los países neutrales, por el escaso desarrollo sanitario existente, sino también las dificultades del laboratorio para establecer cuál era el germen responsable de la pandemia. De hecho, fue imposible comprobar que el bacilo de Pfeiffer (o Haemophilus influenzae) era la bacteria causante de la gripe, como Richard Pfeiffer había propuesto en 1892 [4]. Se aislaron varios microbios distintos, pero no se pudo demostrar ni hubo consenso para considerar uno de ellos como responsable [5]. De hecho, hasta 1933 no se aisló el primer virus de la gripe y desde 1936 se contó con la primera vacuna específica [6]. 
Sin embargo, la grave situación exigía una respuesta. Se utilizaron las tradicionales medidas de higiene pública ante las epidemias (aislamiento de personas enfermas, desinfecciones, cuarentenas, clausura de actividades colectivas o el uso de mascarillas), pero con un sentimiento de impotencia ante la magnitud alcanzada por la pandemia. Este sentimiento motivó que, pese a no clarificarse la etiología de la gripe, se prepararan vacunas contra uno o varios de los gérmenes que el laboratorio aislaba, que fueron aplicadas generalmente al final del segundo brote y, como mucho, podían prevenir las complicaciones pulmonares bacterianas de la gripe [5]. Esta respuesta fue básicamente similar en los países occidentales. Junto al tratamiento sintomático con gran variedad de recursos, se usaron sueros contra algunas de las bacterias aisladas por el laboratorio, con limitada eficacia contra las complicaciones.

La gran mortalidad producida, pese a los esfuerzos profilácticos y terapéuticos realizados, generó múltiples reflexiones sobre los factores relacionados con ella. En el caso de España, coincidiendo con el desarrollo del segundo brote, una parte de los médicos relacionó la magnitud de la pandemia con las malas condiciones socioeconómicas e higiénico-sanitarias de la población, junto con la falta de una legislación sanitaria moderna, de infraestructuras y profesionales sanitarios adecuados, preparando diversos proyectos de ley de profilaxis pública de las enfermedades infecciosas para evitar situaciones similares. En dichos proyectos se incluyeron no solo medidas de mejora y reforma sanitaria, sino también la instauración de los seguros sociales o, al menos, del seguro obligatorio de enfermedad. Igualmente, se diseñó y discutió un completo "Plan Nacional de Reforma Sanitaria", que incluía la instauración de un Ministerio de Sanidad. Estas iniciativas no prosperaron, pero algunas de las medidas propuestas en ellas fueron aprobadas con posterioridad a la pandemia. Sin embargo, otras se olvidaron y se perdió la oportunidad de corregir o, al menos, disminuir las desigualdades, así como de modernizar la ciencia y la sanidad en España [3,7].

Lo ocurrido durante la gripe de 1918-1919, que puso en jaque a la sociedad del momento y mostró sus limitaciones y la necesidad de buscar soluciones plurales, nos debería servir para aprovechar la oportunidad que nos brinda la actual pandemia de CoviD-19, que está mostrando igualmente su globalidad y complejidad, para otorgar a las desigualdades sociales un papel primordial y replantearnos nuestro modelo socioeconómico, que debe ser distinto del actual, marcado por el neoliberalismo imperante desde hace décadas, en el que las personas y sus necesidades más básicas no tienen cabida. No se trata, por tanto, solo de encontrar la vacuna contra el nuevo virus o un tratamiento específico, sino de corregir las desigualdades, para propiciar el acceso a dichos recursos, cuando estén disponibles.

María Isabel Porras Gallo

Catedrática de Historia de la Ciencia, de la Facultad de Medicina de Ciudad Real, Universidad de CastillaLa Mancha. Directora del Grupo de Investigación Salud, historia y sociedad (SALHISOC) de la misma universidad. Investigadora del Centro Regional de Investigaciones Biomédicas (CRIB).

\section{Referencias}

1. Taubenberger JK, Morens DM. 1918 Influenza: The mother of all pandemics. Emerg Infect Dis. 2006,12(1):15-22.

2. Porras Gallo MI. Un reto para la sociedad madrileña: la epidemia de gripe de 1918-1919. Madrid: Editorial Complutense, CAM; 1997.

3. Porras Gallo MI. La lucha contra las enfermedades “evitables” en España y la pandemia de gripe de 1918-19. Dynamis. 1994;14:159-83.

4. Théodorides J. La microbiología médica. En: Laín Entralgo P., director. Historia universal de la medicina. Vol. 6. Barcelona: Salvat; 1974. pp. 175-192.

5. Porras Gallo MI. Sueros y vacunas en la lucha contra la pandemia de gripe de 1918-1919 en España. Asclepio. 2008;60(2):261-88.

6. Kilbourne ED. A race with evolution: A history of influenza vaccines. En: Plotkin SA, editor. History of Vaccine Development. New York: Springer; 2011. pp. 137-144.

7. Porras Gallo MI, Ramírez Ortega M. Los efectos de la pandemia de 1918-19 en la lucha contra la gripe en España: el papel de los cambios de percepción del riesgo y la posterior creación de la oms. En: Ferreira A., coordinador. A gripe espanhola de 1918. Guimeräes: Casa de Sarmento; 2020. pp. 13-30. 